\title{
Pelatihan Bagi Kader Posyandu Penyakit Tidak Menular (PTM)
}

\author{
L Lismayanti ${ }^{*}$, I Rosidawati \\ Universitas Muhammadiyah Tasikmalaya \\ Email: *lilis.lismayanti@umtas.ac.id
}

\begin{abstract}
ABSTRAK
Program Indonesia Sehat bertujuan untuk meningkatkan derajat kesehatan melalui upaya kesehatan dan pemerataan pelayanan kesehatan. Sisi positif dari keberhasilan pembangunan kesehatan diantaranya adalah dengan meningkatnya Umur Harapan Hidup. Namun memiliki dampak negatif yaitu meningkatnya angka kejadian penyakit degeneratif salah satunya adalah hipertensi. Hipertensi sering disebut "silent killer" karena bisa muncul tanpa gejala atau tandatanda peringatan, sehingga banyak yang tidak menyadarinya sehingga semakin meningkatnya prevalensi penyakit hipertensi. Luasnya wilayah kerja dan kurangnya tenaga kesehatan, dapat menimbulkan kurangnya akses masyarakat terhadap pelayanan kesehatan, sehingga lansia yang mengalami hipertensi kurang dapat mengontrol keadaan penyakitnya. Kader Posyandu Penyakit Tidak Menular (PTM) dapat menjadi jajaran pertama dalam menjangkau masyarakat, ketika tenaga kesehatan tidak ada. Kader Posyandupun dapat menjadi perpanjangan tangan dalam meningkatkan pengetahuan dan pemahaman masyarakat tentang hipertensi, bahkan kaderpun dapat melakukan pemeriksaan tekanan darah secara mandiri. Tujuan dari pengabdian kepada masyarakat ini adalah kegiatan IbM bagi Kader Posyandu PTM khususnya di Kelurahan Bantarsari dalam bentuk penyuluhan tentang hipertensi dan pelatihan pengukuran tekanan darah. Populasi dan sampel dalam pengabdian ini adalah seluruh kader di kelurahan Bantarsari sebanyak 24 orang. Data dikumpulkan dengan menggunakan kuesioner dalam bentuk pertanyaan untuk mengetahui pengetahuan peserta sebelum dan sesudah pelatihan dan daftar tilik untuk mengukur keterampilan. Analisis data menggunakan uji Paired-Samples $T$ Test. Adapun bahan yang digunakan adalah alat pengukur tekanan darah yaitu sphygmomanometer digital merek OMRON dengan menggunakan baterai baru. Hasil dari kegiatan ini adalah Semua kader berjenis kelamin perempuan, dengan rentang usia 21-45 tahun. Latar belakang pendidikan kader 79,16 \% lulusan SMA dan 20,84\% lulusan SMP. Hasil analisis uji Paired-Samples T Test didapatkan nilai p Value 0,000 yang artinya ada pengaruh penyuluhan dan pelatihan yang dilakukan terhadap pengetahuan kader tentang pengukuran tekanan darah. Kesimpulannya penyuluhan dan pelatihan kepada kader memiliki pengaruh yang baik dalam peningkatan pengetahuannya, sehingga diharapkan dapat menurunkan angkat kejadian hipertensi di daerah binaannya.
\end{abstract}

Kata Kunci: Kader, PTM, Tekanan Darah

\begin{abstract}
The Healthy Indonesia Program aims to improve health status through health efforts and equitable health services. The positive side of the success of health development is the increasing life expectancy. But it has a negative impact, namely the increasing incidence of degenerative diseases, one of which is hypertension. Hypertension is often called the "silent killer" because it can appear without symptoms or warning signs, so many do not realize it so that the prevalence of hypertension increases. The breadth of the work area and the lack of health workers, can lead to a lack of public access to health services, so the elderly who have hypertension are less able to control the condition of the disease. Cadres of Non-Communicable Diseases Posyandu (PTM) can be the first line in reaching the community, when health workers are not available. Posyand cadres can also be an extension of their hands in increasing people's knowledge and understanding of
\end{abstract}


hypertension, even cadres can carry out blood pressure checks independently. The purpose of community service is IbM activities for Posyandu cadres of PTM, especially in Kelurahan Bantarsari in the form of counseling about hypertension and training in blood pressure measurement. The population and sample in this service were 24 cadres in Bantarsari village. Data was collected using a questionnaire in the form of questions to find out the knowledge of participants before and after training and a checklist to measure skills. Data analysis using the Paired-Samples $\mathrm{T}$ Test. The material used is a blood pressure measuring device, the OMRON brand digital sphygmomanometer using a new battery. The results of this activity are all female cadres, with a age range of $21-45$ years. Educational background for cadres is $79.16 \%$ of high school graduates and $20.84 \%$ of junior high school graduates. The results of the Paired-Samples T Test analysis obtained $\mathrm{p}$ value 0,000 which means that there is an influence of counseling and training conducted on cadre knowledge about blood pressure measurement. In conclusion, counseling and training for cadres has a good influence in increasing their knowledge, so it is expected to reduce the incidence of hypertension in their target areas.

Keywords: Cadre, PTM, Blood Pressure 


\section{PENDAHULUAN}

Program Indonesia Sehat bertujuan untuk meningkatkan derajat kesehatan melalui upaya kesehatan dan pemerataan pelayanan kesehatan. Pelayanan kesehatan yang merata menjadi faktor pendukung dalam keberhasilan pembangunan kesehatan. Sisi positif dari keberhasilan pembangunan kesehatan diantaranya adalah dengan meningkatnya Umur Harapan Hidup (UHH). Peningkatan Umur Harapan Hidup (UHH) ini berdampak pada bertambahnya populasi usia lanjut. Hal ini menimbulkan masalah baru, karena populasi usia lanjut sangat rentan dengan berbagai penyakit menular maupun penyakit tidak menular (PTM). Diantara penyakit tidak menular yang sering menjadi masalah pada populasi usia lanjut adalah penyakit hipertensi (Baradero, 2008)

Hipertensi sering disebut "silent killer" karena bisa muncul tanpa gejala atau tandatanda peringatan, sehingga banyak yang tidak menyadarinya (Baradero, 2008; Brunner \& Suddarth, 2013). Kondisi demikian menjadi salah satu penyebab semakin meningkatnya prevalensi penyakit hipertensi (Yogiantoro, 2010). Sampai saat ini, data hipertensi yang lengkap sebagian besar berasal dari negara-negara maju. Data dari The National Health and Nutrition Examination Survey (NHNES) menunjukkan bahwa dari tahun 1999-2000 insiden hipertensi pada orang dewasa Amerika sekitar 29-31\%. WHO sendiri menyampaikan sebanyak 1 milyar orang di dunia atau 1 dari 4 orang dewasa menderita hipertensi. Hipertensi esensial merupakan 95\% dari seluruh kasus hipertensi (Yogiantoro, 2010).

Kejadian hipertensi di Indonesia dapat dilihat berdasarkan hasil analisis lebih lanjut dari Badan Penelitian dan Pengembangan Kesehatan Kementrian Kesehatan RI tahun 2013. Hasil pendataan Riskesdas 2013 terjadi peningkatan prevalensi hipertensi berdasarkan wawancara dari 7,6\% pada tahun 2007 menjadi 9,5\% pada tahun 2013 . Melalui pengukuran hipertensi pada umur $\geq 18$ tahun didapat sebesar 25,8\%, tertinggi di Bangka Belitung (30,9\%), diikuti Kalimantan Selatan (30,8\%), Kalimantan Timur (29,6\%), dan Jawa Barat (29,4\%) (Kemenkes, 2013).

Jumlah pasien hipertensi di kota Tasikmalaya pada tahun 2013 tercatat sebanyak 13.187 jiwa. Sedangkan data tahun 2014 terjadi peningkatan jumlah pasien hipertensi yakni 14.876 jiwa, dan pada tahun 2015 didapatkan data sebanyak 13.710 jiwa. Data hipertensi tersebut merupakan hasil rekapan data hipertensi dari puskesmas-puskesmas yang ada di wilayah kota Tasikmalaya. Salah satunya adalah dari UPTD Puskesmas Bantarsari. Data penderita hipertensi di UPTD Puskesmas Bantarsari pada tahun 2013 sebanyak 3.134 orang, tahun 2014 sebanyak 1.835 orang, dan pada tahun 2015 sebanyak 1.815 orang (Sumber: rekam medik UPTD Puskesmas Bantarsari tahun 2016). Penyakit Hipertensi di UPTD Puskesmas Bantarsari menempati urutan kedua dalam 10 besar penyakit dan urutan pertama pada kasus penyakit tidak menular di setiap tahunnya.

Kedaruratan hipertensi terjadi apabila peningkatan tekanan darah harus diturunkan dalam 1 jam. Peningkatan tekanan darah akut yang mengancam jiwa ini memerlukan penanganan segera dalam perawatan intensif karena dapat menimbulkan kerusakan serius pada organ lain di tubuh. Kedaruratan hipertensi terjadi pada penderita dengan hipertensi yang tidak terkontrol atau mereka yang tiba-tiba menghentikan pengobatan. (Brunner \& Suddarth, 2013), artinya bahwa hipertensi tidak perlu menjadi kedaruratan apabila terkontrol dengan baik. Melalui peran kader Pos Pelayanan Terpadu Penyakit Tidak Menular (Posyandu PTM) hipertensi ini dapat terkontrol.

Berdasarkan data yang diperoleh, maka penulis merasa penting melakukan pengabdian kepada masyarakat yang bertujuan untuk meningkatkan pengetahuan dan keterampilannya dalam mendeteksi dini dan mengontrol hipertensi dengan cara 
memberikan penyuluhan tentang hipertensi, pentingnya mengontrol hipertensi dan bagaimana cara mengukur tekanan darah.

\section{BAHAN DAN METODE}

Jenis pengabdian ini adalah ipteks bagi masyarakat yaitu pelatihan bagi kader Posyandu PTM tentang hipertensi, pentingnya mengontrol hipertensi dan cara mengukur tekanan darah, yang dilaksanakan di Kelurahan Bantarsari Kecamatan Bungursari Kota Tasikmalaya, yang dilaksanakan pada tanggal 15 Juni 2017. Populasi dan sampel dalam pengabdian ini adalah seluruh kader di kelurahan Bantarsari sebanyak 24 orang.

Data dikumpulkan dengan menggunakan kuesioner dalam bentuk pertanyaan untuk mengetahui pengetahuan peserta sebelum dan sesudah pelatihan dan daftar tilik untuk mengukur keterampilan. Analisis data menggunakan uji Paired-Samples T Test. Adapun bahan yang digunakan adalah alat pengukur tekanan darah yaitu sphygmomanometer digital merek OMRON dengan menggunakan baterai baru.

\section{HASIL}

Pelatihan kader Posyandu PTM diikuti oleh 24 kader. Semua kader berjenis kelamin perempuan, dengan rentang usia 21-45 tahun. Latar belakang pendidikan kader 79,16\% lulusan SMA dan 20,84\% lulusan SMP.

Pengetahuan dan keterampilan kader sebelum dan sesudah dilakukan pelatihan seperti terlihat pada tabel 1 .

Tabel 1. Pengetahuan kader sebelum dan sesudah dilakukan pelatihan

\begin{tabular}{lccc}
\hline \multicolumn{1}{c}{ Variabel } & N & Mean & Standar Deviasi \\
\hline Pengetahuan sebelum pelatihan & 24 & 38.75 & 7.697 \\
Pengetahuan setelah pelatihan & 24 & 81.04 & 5.894 \\
\hline
\end{tabular}

Sumber : Data Primer, 2017

Berdasarkan tabel. 1 menunjukkan bahwa dari 24 orang kader rata-rata pengetahuan sebelum pelatihan adalah 38,75 dengan standar deviasi 7.697. sedangkan rata-rata pengetahuan kader setelah pelatihan adalah 81,04 dengan standar deviasi 5.894.

Tabel 2. Keterampilan kader sebelum dan sesudah dilakukan pelatihan

\begin{tabular}{lcccc}
\hline \multicolumn{1}{c}{ Variabel } & $\mathrm{N}$ & Mean & $\begin{array}{c}\text { Standar } \\
\text { Deviasi }\end{array}$ & Standar Eror Mean \\
\hline Keterampilan sebelum pelatihan & 24 & 20.83 & 4.341 & 0.886 \\
Keterampilan setelah pelatihan & 24 & 81.67 & 4.082 & 0.833 \\
\hline
\end{tabular}

Sumber : Data Primer, 2017

Berdasarkan tabel. 2 menunjukkan bahwa dari 24 orang kader rata-rata keterampilan sebelum pelatihan adalah 20.83 dengan standar deviasi 4.341. sedangkan rata-rata keterampilan kader setelah pelatihan adalah 81.67 dengan standar deviasi 4.082. 
Adapun hasil analisis pengaruh pelatihan terhadap pengetahuan dan keterampilan kader di Kelurahan Bantarsari seperti terlihat pada Tabel 3.

Tabel 3. Pengaruh Pelatihan terhadap pengetahuan dan keterampilan kader di Kelurahan

\begin{tabular}{|c|c|c|c|c|c|}
\hline Variabel & $\mathrm{N}$ & Mean & $\begin{array}{l}\text { Standar } \\
\text { Deviasi }\end{array}$ & $\begin{array}{c}\text { Standar } \\
\text { Eror } \\
\text { Mean }\end{array}$ & $\begin{array}{c}\mathrm{P} \\
\text { Value }\end{array}$ \\
\hline $\begin{array}{l}\text { Pengetahuan sebelum dan } \\
\text { sesudah pelatihan }\end{array}$ & 24 & -42.292 & 9.086 & 1.885 & 0,000 \\
\hline $\begin{array}{l}\text { Keterampilan sebelum dan } \\
\text { setelah pelatihan }\end{array}$ & 24 & -60.833 & 6.539 & 1.355 & 0,000 \\
\hline
\end{tabular}

Sumber : Data Primer, 2017

Berdasarkan tabel. 3 menunjukkan bahwa dari 24 orang kader rata-rata pengetahuan sebelum dan sesudah pelatihan adalah -42.292 dengan standar deviasi 9.086, standar eror Mean 1.885 dengan nilai $P$ Value 0,000 lebih kecil dari 0,05 $\alpha$ yang artinya ada pengaruh pelatihan terhadap pengetahuan kader di kelurahan Bantarsari. Sedangkan rata-rata keterampilan sebelum dan sesudah pelatihan adalah -60.833dengan standar deviasi 6.539, standar eror Mean 1.355dengan nilai P Value 0,000 lebih kecil dari 0,05 $\alpha$ yang artinya ada pengaruh pelatihan terhadap keterampilan kader di kelurahan Bantarsari.

\section{PEMBAHASAN}

Program Ipteks bagi masyarakat (IbM) Bagi Kader ini merupakan kegiatan pengabdian kepada masyarakat dilaksanakan dengan tujuan untuk melatih kader Posyandu PTM tentang hipertensi di Kelurahan Bantarsari. Adapun kegiatan yang dilakukan adalah penyuluhan dan pelatihan pengukuran tekanan darah. Pelatihan kader Posyandu PTM diikuti oleh 24 kader. Semua kader berjenis kelamin perempuan, dengan rentang usia 2145 tahun. Latar belakang pendidikan kader 79,16 \% lulusan SMA dan 20,84\% lulusan SMP.

Berdasarkan tabel. 1 menunjukkan bahwa dari 24 orang kader rata-rata pengetahuan sebelum pelatihan adalah 38,75 dengan standar deviasi 7.697. sedangkan rata-rata pengetahuan kader setelah pelatihan adalah 81,04 dengan standar deviasi 5.894. Berdasarkan tabel. 2 menunjukkan bahwa dari 24 orang kader rata-rata keterampilan sebelum pelatihan adalah 20.83 dengan standar deviasi 4.341. sedangkan rata-rata keterampilan kader setelah pelatihan adalah 81.67 dengan standar deviasi 4.082. Hasil analisis uji Paired-Samples T Test didapatkan nilai p Value 0,000 yang artinya ada pengaruh penyuluhan dan pelatihan yang dilakukan terhadap pengetahuan kader tentang pengukuran tekanan darah.

Hipertensi sering disebut "silent killer" karena bisa muncul tanpa gejala atau tandatanda peringatan, sehingga banyak yang tidak menyadarinya (Baradero, 2008; Brunner \& Suddarth, 2013). Kondisi demikian menjadi salah satu penyebab semakin meningkatnya prevalensi penyakit hipertensi (Yogiantoro, 2010). Kedaruratan hipertensi terjadi apabila peningkatan tekanan darah harus diturunkan dalam 1 jam. Peningkatan tekanan darah akut yang mengancam jiwa ini memerlukan penanganan segera dalam perawatan intensif karena dapat menimbulkan kerusakan serius pada organ lain di tubuh. Kedaruratan hipertensi terjadi pada penderita dengan hipertensi yang tidak terkontrol atau mereka yang tiba-tiba 
menghentikan pengobatan. (Brunner \& Suddarth, 2013), artinya bahwa hipertensi tidak perlu menjadi kedaruratan apabila terkontrol dengan baik.

Permasalahan hipertensi tidak dapat diselesaikan hanya oleh tenaga kesehatan, tetapi perlu ada nya kemitraan antara pasien, tenaga kesehatan dan masyarakat melalai pemberdayaan masyarakat. Posyandu PTM merupakan salah satu bentuk pemberdayaan masyarakat yang dapat menjembatani antara tenaga kesehatan dengan pasien. Maka dari itu kader Posyandu PTM akan menjadi jajaran terdepan dalam mentransfer pengetahuan, pemahaman dan keterampilan dalam menanganan hipertensi, sehingga kader menjadi sangat penting untuk mendapat pemahaman tentang hipertensi berkenaan dengan cara deteksi dini dan pemeriksaan tekanan darah.

Asumsi penulis setelah menganalisis hasil pengabdian kepada masyarakat bahwa penyuluhan dan pelatihan pengukuran tekanan darah pada kader memiliki pengaruh untuk meningkatkan pengetahuan dan keterampilan para kader hal tersebut karena salahsatu faktor yang mempengaruhi pengetahuan seseorang adalah pemberian informasi. Sejalan dengan Notoatmodjo (2015) bahwa pendidikan kesehatan dalam jangka waktu pendek dapat menghasilkan perubahan dan peningkatan pengetahuan individu, kelompok, dan masyarakat. Diperkuat oleh temuan Kurrachman (2003 dalam Sukiarso, 2007), bahwa pelatihan dengan metode ceramah yang disertai diskusi, simulasi, dan praktik dapat meningkatkan pengetahuan.

Pengukuran tekanan darah merupakan salah satu kegiatan posyandu PTM yang dilakukan para kader di wilayah kerjanya masing-masing. Kader PTM mempunyai potensi yang sangat besar karena kader sangat dekat dengan masyarakat di wilayah sendiri, sehingga pasien dengan hipertensi menjadi lebih terkontrol tekanan darahnya. Terkontrolnya tekanan darah pada pasien bisa menurunkan kejadian komplikasi hipertensi yang lebih parah. Pemberian pelatihan pada kader merupakan salah satu cara untuk meningkatkan pengetahuan, keterampilan serta sikap pada kader. Sejalan dengan sianturi (2013 dalam Maulida dan Henny, 2016) bahwa pelatihan merupakan suatu proses belajar mengajar terhadap pengetahuan dan keterampilan tertentu serta sikap agar peserta semakin terampil dan mampu melaksanakan tanggung jawabnya dengan semakin baik, sesuai dengan standar. Adanya Peningkatan pengetahuan dan keterampilan akan di nilai dari hasil sesudah pelatihan, sehingga sebelum maupun sesudah dilakukan pelatihan diperlukan adanya evaluasi.

Setelah dilakukan pelatihan pengukuran tekanan darah diharapkan kader PTM mampu termotivasi untuk mempertahankan serta meningkatkan kemampuan keterampilan tersebut. Hal tersebut sejalan dengan Zainul dan Nasution (2005) dalam Sukiarso (2007) bahwa keberhasilan suatu pelatihan dapat menjadi motivasi untuk mempertahankan dan meningkatkan hasilnya.

\section{KESIMPULAN DAN SARAN}

Program Ipteks bagi masyarakat (IbM) Bagi Kader ini merupakan kegiatan pengabdian kepada masyarakat dilaksanakan dengan tujuan untuk melatih kader Posyandu PTM tentang hipertensi di Kelurahan Bantarsari. Adapun kegiatan yang dilakukan adalah penyuluhan dan pelatihan pengukuran tekanan darah. Pelatihan kader Posyandu PTM diikuti oleh 24 kader. Semua kader berjenis kelamin perempuan, dengan rentang usia 2145 tahun. Latar belakang pendidikan kader 79,16 \% lulusan SMA dan 20,84\% lulusan SMP. Hasil analisis uji Paired-Samples T Test didapatkan nilai $\mathrm{p}$ Value 0,000 yang artinya 
ada pengaruh penyuluhan dan pelatihan yang dilakukan terhadap pengetahuan kader tentang pengukuran tekanan darah. Kesimpulannya penyuluhan dan pelatihan kepada kader memiliki pengaruh yang baik dalam peningkatan pengetahuannya, sehingga diharapkan dapat menurunkan angkat kejadian hipertensi di daerah binaannya.

\section{UCAPAN TERIMAKASIH}

Ucapan terimakasih penulis sampaikan kepada Universitas Muhammadiyah Tasikmalaya yang telah memberikan dana untuk melaksanakan kegiatan Pengabdian Kepada Masyarakat. Secara khusus ucapan terimakasih penulis sampaikan kepada 1) Rektor Universitas Muhammadiyah Tasikmalaya, 2) Ketua Lembaga Penelitian dan Pengabdian Masyarakat (LPPM) Universitas Muhammadiyah Tasikmalaya (Mujiarto, S.T., M.T.), 3) Kepala Puskesmas Bantarsari dan 4) Para Kader di Kelurahan Bantarsari.

\section{DAFTAR PUSTAKA}

Baradero, M. (2008). Klien Gangguan Kardiovaskular Seri Asuhan Keperawatan. Jakarta: EGC

Brunner \& Suddarth. (2013). Buku Ajar Keperawatan Medikal Bedah Edisi 8 volume 2. Jakarta: EGC

Kementrian Kesehatan. (2013). Riset Kesehatan Dasar. Jakarta

Maulida, K.W \& Heny, P . (2016). Upaya Peningkatan Ketrampilan Kader Posyandu Dalam Pengukuran Tekanan Darah Melalui Pelatihan Kader. ISSN 2086-8510

Notoatmojo, Soekidjo. (2015). Pendidikan dan Perilaku Kesehatan. Jakarta : PT Rineka Cipta

Rekam medik UPTD Puskesmas Bantarsari Tahun 2016

Sukiarso, E. (2007). Pengaruh Pelatihan dengan Metode Belajar Berdasarkan Masalah terhadap Pengetahuan dan Keterampilan Kader Gizi dalam Kegiatan Posyandu. Tesis tidak diterbitkan. FKM Universitas Diponegoro, Semarang.

Yogiantoro, M. (2010). Hipertensi Essensial: Buku Ajar Ilmu Penyakit Dalam. Jakarta : FKUI 


\section{LAMPIRAN}

Dokumentasi Kegiatan
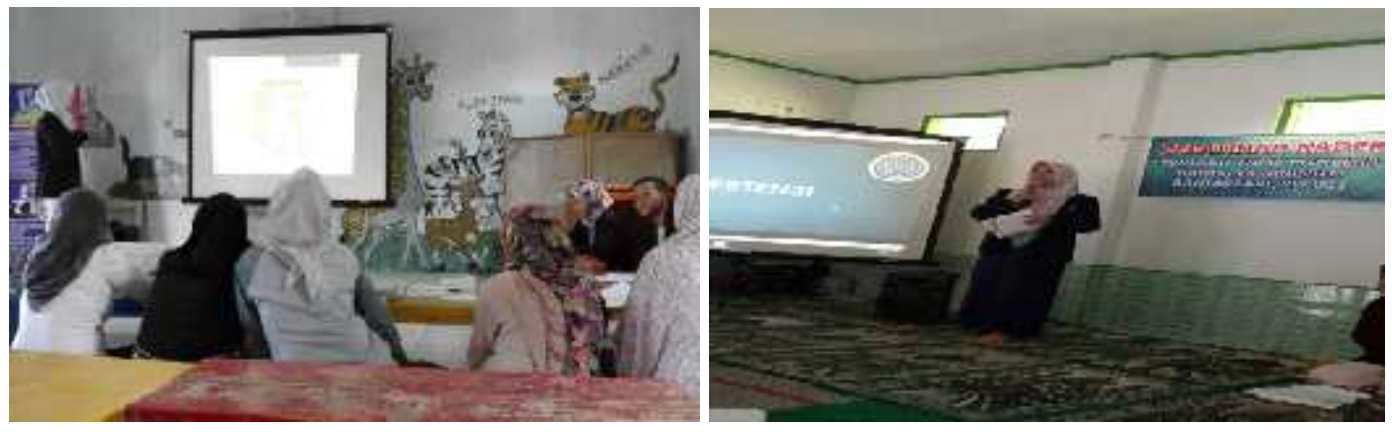

Gambar 1. Mahasiswa sedang menjelaskan materi penyakit tidak menular

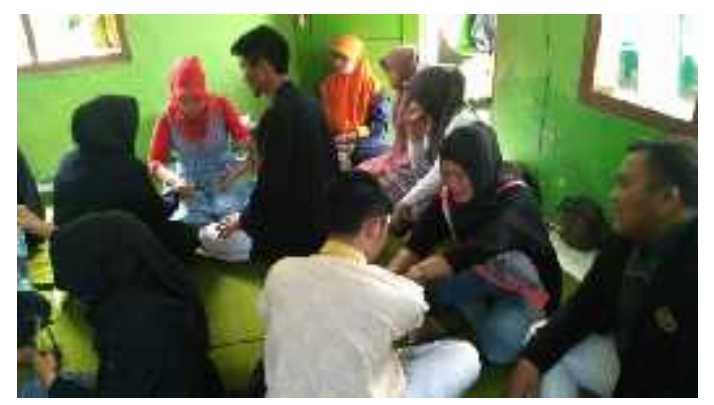

Gambar 2. Kader sedang mendemontasikan cara pengukuran tekanan darah

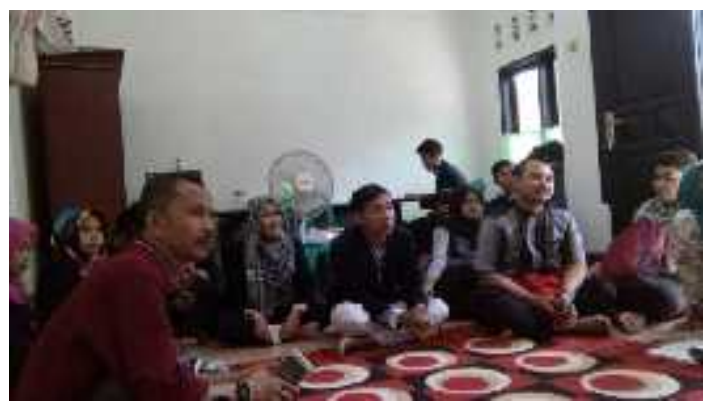

Gambar 3. Dosen dan Mahasiswa sedang mengevaluasi kemampuan kader melakukan penyuluhan 


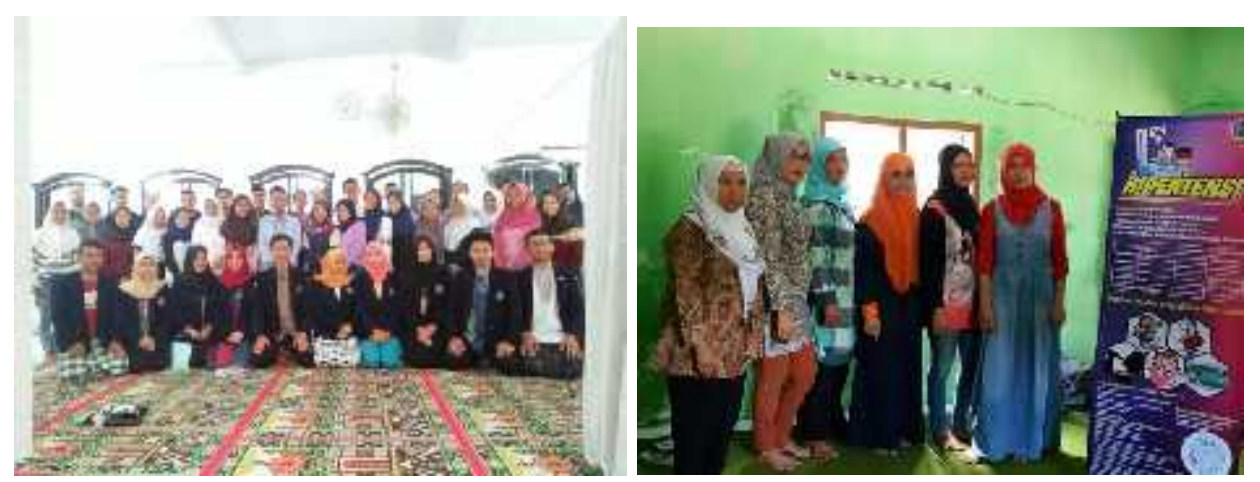

Gambar 4. Peserta Pelatihan dan fasilitator

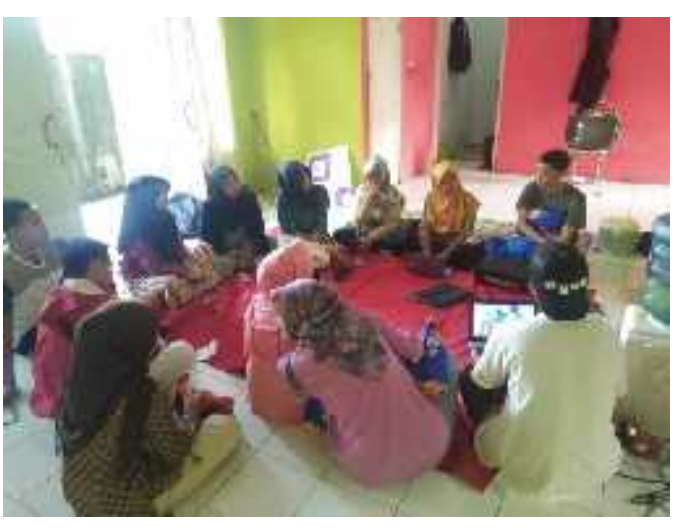

Gambar 5. Peserta Pelatihan Terbaik

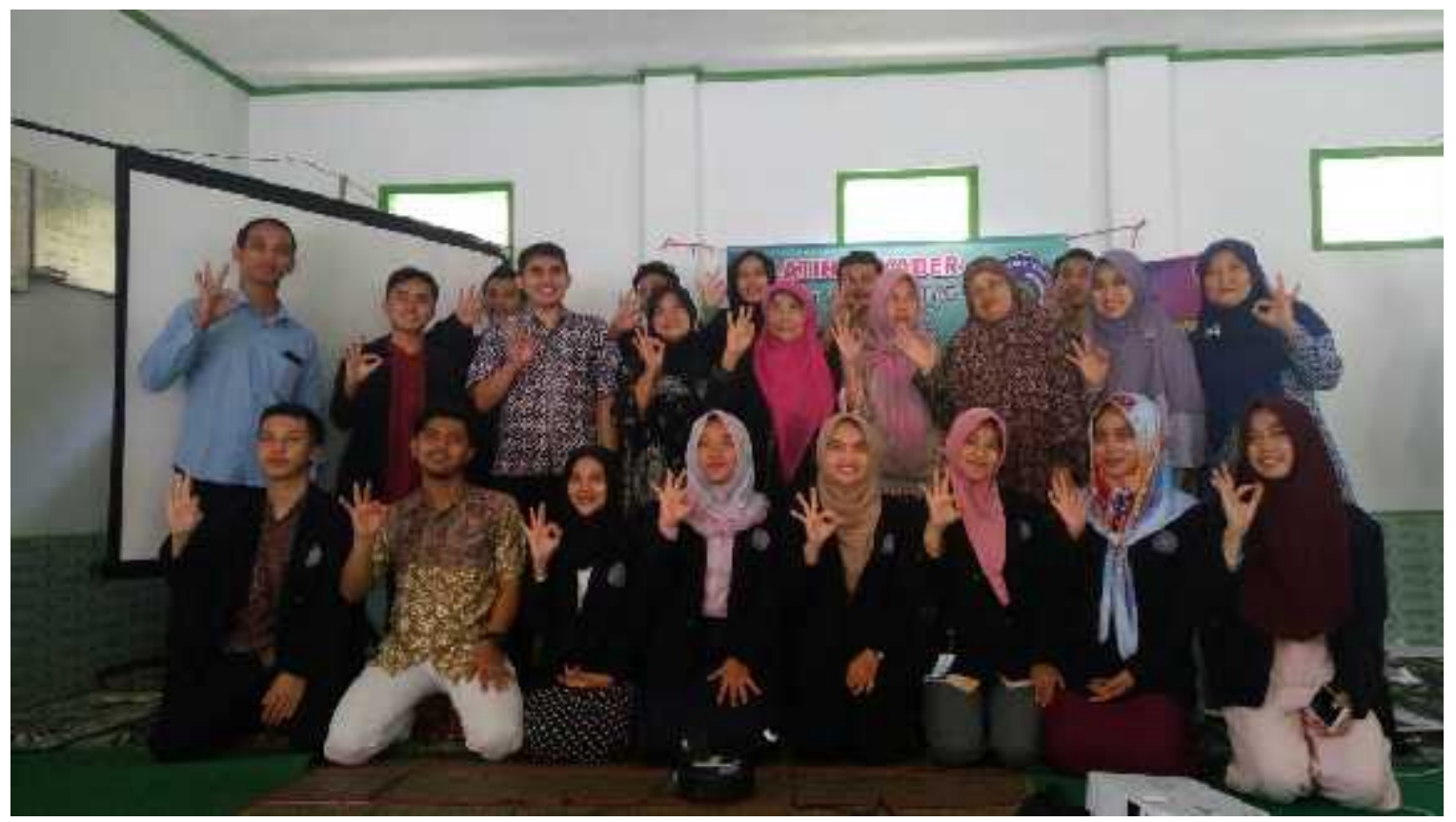

Gambar 6. Dokumentasi akhir kegiatan 